Revista de Filología Románica

ISSN: 0212-999X

http://dx.doi.org/10.5209/RFRM.58150

\title{
El reencuentro con don Alonso
}

María Victoria Navas Sanchéz-Élez y Carmen Mejía Ruiz ${ }^{1}$

Llegó enero de 2016 y los discípulos de la Titulación de Filología Románica de la Universidad Complutense de Madrid nos propusimos llevar a cabo una idea común, la celebración del centenario de nuestro maestro.

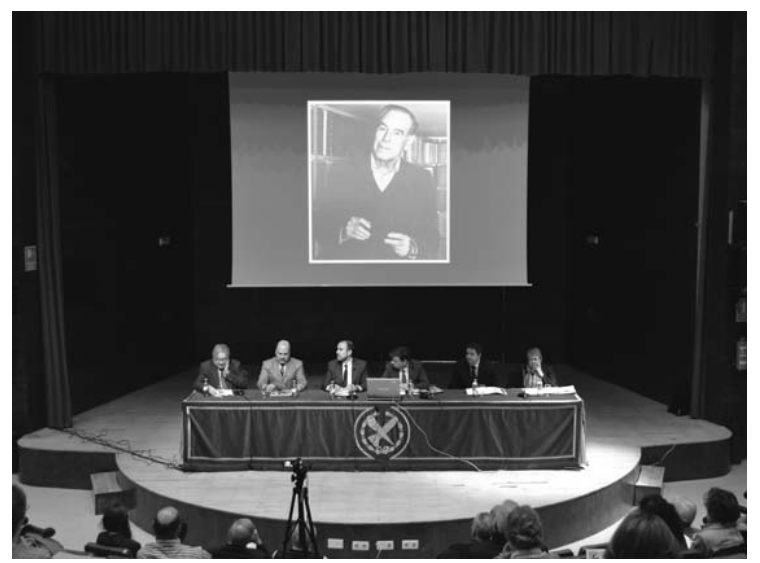

Figura 1. Acto de apertura Alonso Zamora Vicente. 100 años de su nacimiento.

Nos reunimos primero los más próximos, Eugenia Popeanga, Jesús Sánchez Lobato, Denis Canellas, María Josefa Postigo, Juan Miguel Ribera, María Victoria Navas y Carmen Mejía para hablar del proyecto. Poco a poco fuimos contactando con sus discípulos esparcidos por las diferentes universidades españolas. La llamada tuvo una calurosa acogida y gracias a la ayuda de los jóvenes, en este caso Lidia López Teijeiro, lectora de gallego en la Titulación de Filología Románica, organizamos un encuentro para celebrar el Centenario de nuestro añorado maestro en la Facultad de Filología de la Universidad Complutense, que decidimos denominar Alonso Zamora Vicente. 100 años de su nacimiento.

El acto de apertura tuvo lugar el día 18 de abril de 2016 en el Paraninfo de la Facultad de Filología e intervinieron el profesor Carlos Andradas, Rector de la Universidad Complutense, el profesor Eugenio Luján, Decano de la Facultad de Filología, el profesor José Manuel Lucía Megías, Vicedecano de Biblioteca, Cultura y Relaciones Institucionales, la profesora Eugenia Popeanga, Catedrática de Filología Románica y Coordinadora de la Titulación de Filología Románica, don Adrián Guzmán Aparicio, responsable de la Biblioteca Alonso Zamora Vicente en la Casa del Mono en Cáceres y el profesor don José Carlos Rovira, de la Universidad de Alicante y responsable de la Biblioteca Virtual Cervantes.

A continuación tuvo lugar la mesa titulada Alonso Zamora Vicente, Filólogo, moderada por la profesora María Josefa Postigo Aldeamil. Participaron la profesora Paz Battaner, de la Universidad Pompeu Fabra, Mario Pedrazuela, de la Real Aca- 


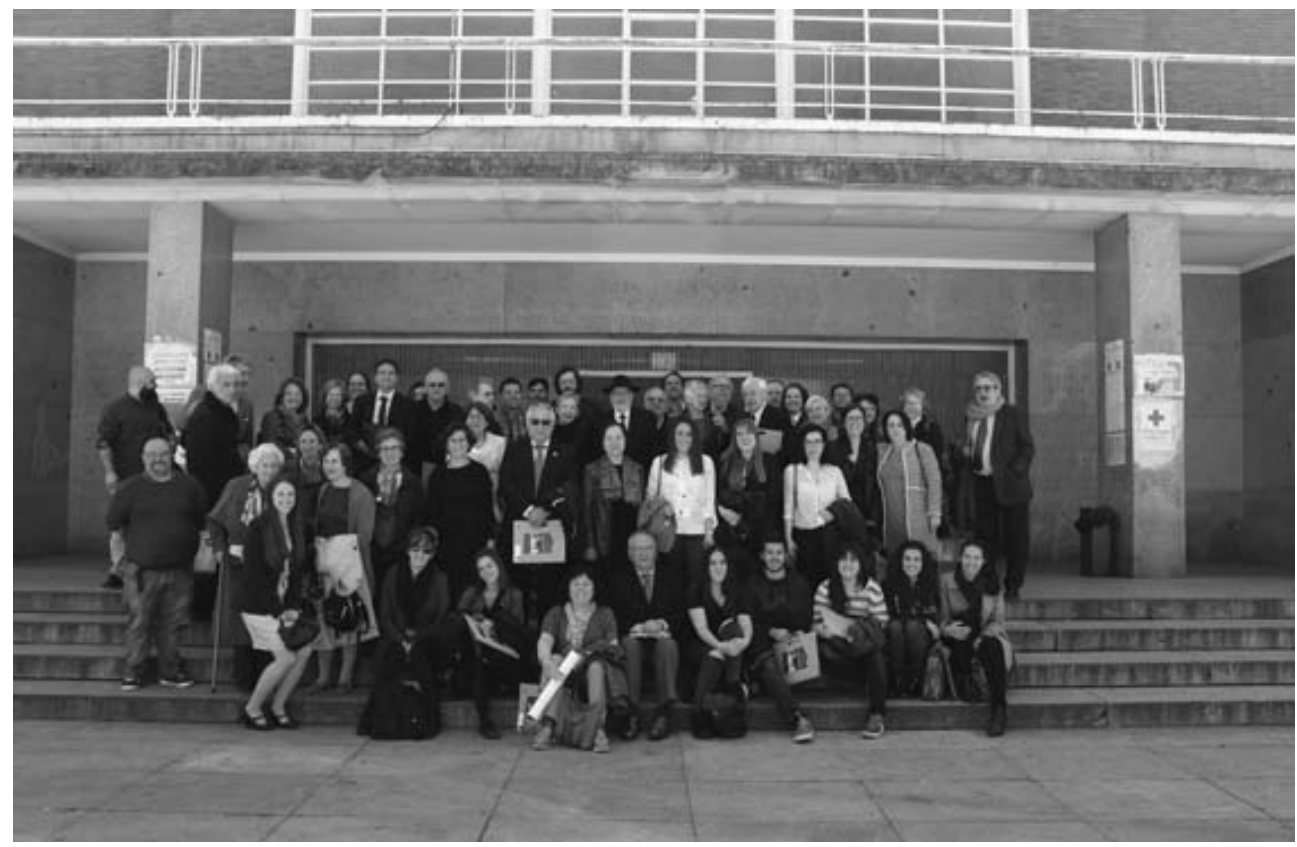

Figura 2. Organización y participantes del homenaje.

demia Española, Francisco Fernández Rei, de la Universidad de Santiago de Compostela y Ana María Cano, de la Universidad de Oviedo. Cada uno de ellos profundizó en los aspectos filológicos en los que Alonso Zamora Vicente trabajó a lo largo de su vida académica e investigadora, dejando muy claro que supo crear una Escuela, hecho que hoy día es prácticamente inusual.

Tras la pausa del café se celebró la mesa denominada Alonso Zamora Vicente, Embajador de la lengua española, que moderó la profesora Carmen Mejía Ruiz, de la Universidad Complutense de Madrid. En ella participaron Jesús Sánchez Lobato y Juan Mayor, de la Universidad Complutense Madrid, Berta Pallares, de la Universidad de Copenhague y Marta Baralo, de la Universidad Antonio de Nebrija. Terminó esta mesa con la Presentación de la Biblioteca Virtual Miguel de Cervantes, a cargo de José Carlos Rovira, de la Universidad de Alicante. Se destacó el papel que tuvo Alonso Zamora Vicente en la difusión del español como lengua extranjera, recordando los cursos que dirigió durante muchos años en la Escuela Diplomática de Madrid, organizados por el Ministerio de Asuntos Exteriores y la Agencia Española de Cooperación. Además de aludir al profesor que queda en el recuerdo de los jóvenes como ejemplo a seguir.

Antes del comienzo de la sesión de la tarde se hizo una visita a la Exposición Bibliográfica de Alonso Zamora Vicente en la Biblioteca de la Facultad de Filología, que organizaron Lidia López Teijeiro y María Colóm Jiménez. La mesa, Alonso Zamora Vicente, Escritor, la moderó el profesor Denis Canellas, de la Universidad Complutense, y en ella participaron Francisco de Borja Rodríguez Gutiérrez, de la Universidad de Cantabria y de la Real Sociedad Menéndez Pelayo y el profesor Jorge Urrutia, de la Universidad Carlos III de Madrid, que desarrollaron una emotiva semblanza del escritor. 


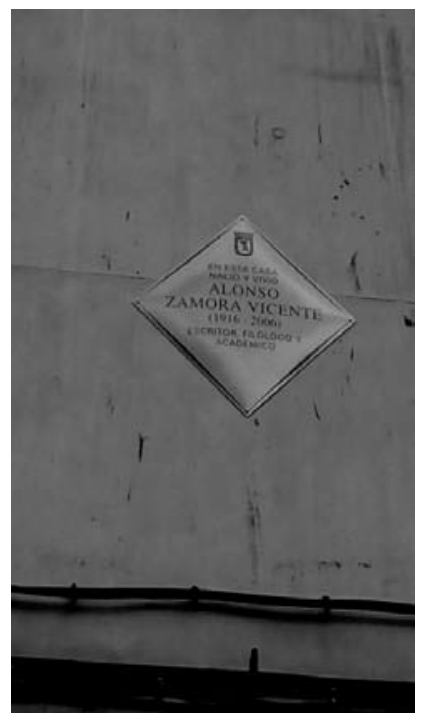

Figura 3. Placa conmemorativa del Ayuntamiento de Madrid.

A continuación tuvo lugar la sesión, Alonso Zamora Vicente, Maestro, moderada por la profesora Eugenia Popeanga, de la Universidad Complutense. En ella participaron, el profesor Antonio Viudas, de la Universidad de Extremadura, los profesores Juan Miguel Ribera LLopis, Pilar Muñoa y Juan Manuel González Martel, de la Universidad Complutense de Madrid, quien cerró con una humana semblanza del maestro, creando una atmósfera de familia entre los participantes.

Durante el debate el profesor Antonio Viudas propuso que se colocase una placa conmemorativa en la casa donde nació el maestro. Esta idea fue apoyada por el comité organizador del centenario.

Cerró el acto la profesora María Victoria Navas, de la Universidad Complutense de Madrid, que presentó el Epílogo de Alonso Zamora Vicente, que RTVE emitió postmortem, el día 14 de marzo de 2006, recuperando la voz del maestro.

Como colofón, Irene, una de las nietas de don Alonso, hija de Juan Zamora Canellada y de Merche Soto, envió un vídeo dirigido a su abuelo, que dejó a los participantes conmovidos y cuyo texto reproducimos en este volumen.

Al día siguiente, 19 de abril, tuvo lugar una sesión sobre la obra de Alonso Zamora Vicente dando voz a Sebastián Stratan, estudiante de doctorado, quien hizo un repaso por la creación zamoranavicentina. A continuación las profesoras Lidia López Teijeiro y María Colom llevaron a cabo un taller de traducción en el que los estudiantes de gallego, portugués, catalán, rumano y

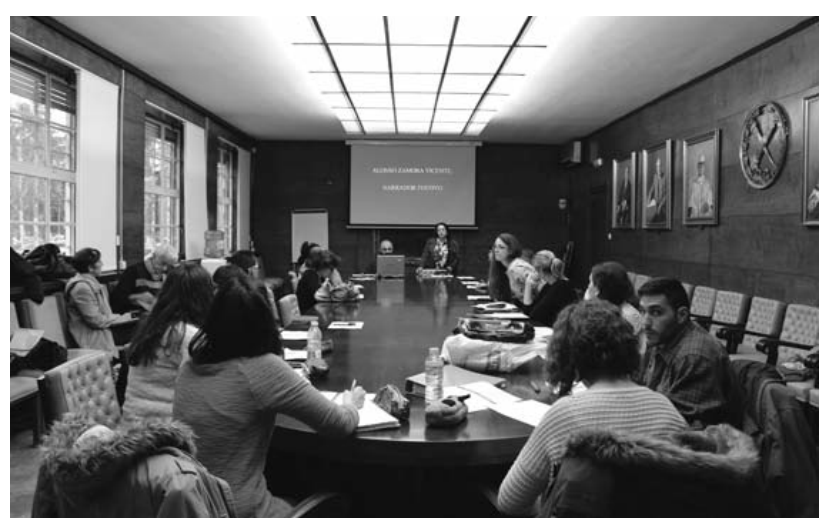

Figura 4. Seminario de traducción multilingue AZV vasco vertieron en las respectivas lenguas unos relatos de Primeras Hojas (1955) de Alonso Zamora Vicente.

Desde el día 18 de abril todos quedamos emplazados a la siguiente convocatoria del centenario que tendría lugar en la Universidad Antonio de Nebrija y en la Real Academia de la Lengua Española, como atinadamente refiere don Manuel VillaCellino en este mismo volumen. Queremos destacar la interpretación que Ana e Isabel Zamora, nietas de don Alonso, hicieron en la Facultad de Filología de la Universidad Complutense, dando voz a una serie de textos teatrales de Alonso Zamora Vicente representados por la actriz Gloria Muñoz. Asimismo, este centenario llegó hasta Cáceres y Malpartida de Cáceres de la mano del profesor Antonio Viudas, quien relata pormenorizadamente este Itinerario Artístico Literario en este volumen y en el que participamos la mayoría de sus discípulos. 
Para terminar con la celebración del centenario al maestro el día 13 de marzo de 2017 el señor D. Antonio Maura, representante de Cultura del Ayuntamiento de Madrid descubrió la placa en la casa donde nació Alonso Zamora Vicente en la Plaza de la Cebada, número 10. En el acto intervinieron: D. Antonio Maura, responsable de Cultura del Ayuntamiento de Madrid, D ${ }^{\mathrm{a}}$ María Nagore Ferrer, Vicerrectora de Extensión Universitaria, en representación del Rector; D. José Manuel Lucía Megías, Vicedecano de Relaciones Institucionales de la Facultad de Filología de la UCM, en representación del Decano; $\mathrm{D}^{\mathrm{a}}$ Eugenia Popeanga, Catedrática de Filología Románica de la UCM y discípula de Alonso Zamora Vicente y D. Alonso Zamora Canellada, hijo de Alonso Zamora Vicente.

Hoy sale a la luz este volumen resultado del centenario que nos convocó a todos los seguidores de Alonso Zamora Vicente. Esperamos que el lector sepa apreciar el esfuerzo que supuso este reconocimiento al maestro y estamos seguros de que don Alonso nos diría: ¡Forajidos! ¡Que seáis buenos!

Gracias a todos por vuestro buen hacer universitario y por vuestro cariño. Gracias, don Alonso, por todo.

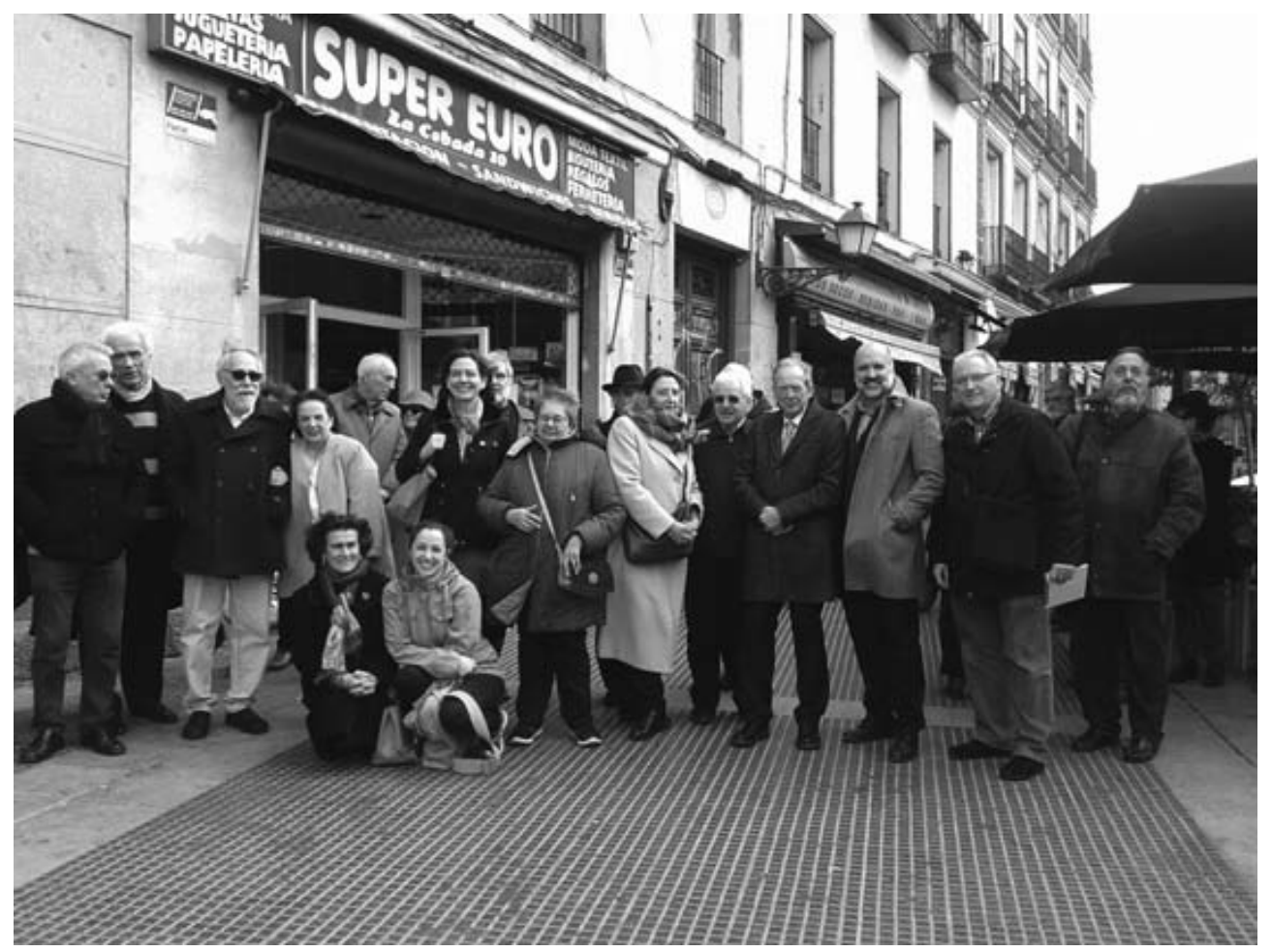

Figura 5. Organización y participantes del homenaje. 